\title{
Omission of axillary lymph node dissection in patients who underwent total mastectomy with 1 or 2 metastatic lymph nodes
}

\author{
Bong Kyun Kim ${ }^{1}$, Byeong-Woo Park², Min Hee Hur 3 , Han-Byoel Lee ${ }^{4}$, Min Ho Park', Joon Jeong ${ }^{6}$, Hyouk Jin Lee, \\ Jina Lee', Dongju Kim', Woo Young Sun'; for the Korean Breast Cancer Society \\ ${ }^{1}$ Department of Surgery, Daejeon St. Mary's Hospital, College of Medicine, The Catholic University of Korea, Seoul, Korea \\ ${ }^{2}$ Department of Surgery, Yonsei University College of Medicine, Seoul, Korea \\ ${ }^{3}$ Department of Surgery, Inha University Hospital, Inha University School of Medicine, Incheon, Korea \\ ${ }^{4}$ Department of Surgery, Seoul National University College of Medicine, Seoul, Korea \\ ${ }^{5}$ Department of Surgery, Chonnam National University Hwasun Hospital, Hwasun, Korea \\ ${ }^{6}$ Department of Surgery, Gangnam Severance Hospital, Yonsei University College of Medicine, Seoul, Korea \\ 'Breast-Thyroid Center, Saegyaero Hospital, Busan, Korea
}

Purpose: Sentinel lymph node biopsy (SLNB) is the standard axillary procedure in early breast cancer patients. In a randomized trial, the survival rates were not different when axillary lymph node dissection (ALND) was omitted in patients with 1 or 2 lymph node metastases who underwent breast conserving surgery. This study aimed to compare the outcomes in patients who underwent total mastectomy (TM) with 1 or 2 metastatic nodes according to the types of axillary surgery. Methods: In total, 79,058 patients registered in the Korean Breast Cancer Society database who underwent TM were included in the analysis. The inclusion criteria were history of TM and SLNB, pathologic T stage 1 or 2, clinically negative axillary lymph nodes, 1 or 2 metastatic axillary lymph nodes, no radiation therapy, and no neoadjuvant therapy. We divided the patients into the SLNB only and SLNB + ALND groups. The groups were matched by propensity scores. We retrospectively analyzed the differences in the overall survival (OS) between the 2 groups.

Results: A total of 883 patients were matched in a 1:4 ratio for the SLNB only and SLNB + ALND groups in the cohort from 1999 to 2014 . There were no significant differences in OS between the 2 groups ( $P=0.413$ ). Subgroup analysis revealed a significant survival benefit in the SLNB + ALND group in the T2 subgroup ( $P=0.013)$.

Conclusion: OS did not differ between the 2 groups in early breast cancer patients with 1 or 2 metastatic axillary lymph nodes who underwent TM. Omission of ALND may be considered in selected patients.

[Ann Surg Treat Res 2020;98(6):283-290]

Key Words: Lymph node dissection, Mastectomy, Sentinel lymph node biopsy, Survival analysis

\section{INTRODUCTION}

Axillary lymph node dissection (ALND), along with mastectomy, has played an important role in the radical treatment and staging of breast cancer since it was introduced by Halstead [1,2]. However, there is a risk of complications such
Received November 7, 2019, Revised March 9, 2020,

Accepted April 9, 2020

Corresponding Author: Woo Young Sun

Department of Surgery, Daejeon St. Mary's Hospital, College of Medicine, The Catholic University of Korea, 64 Daeheung-ro, Jung-gu, Daejeon 34943 , Korea

Tel: +82-42-220-9235, Fax: +82-42-220-9565

E-mail: sun2729@naver.com

ORCID: https://orcid.org/0000-0002-5447-4266
Copyright (c) 2020, the Korean Surgical Society

(c) Annals of Surgical Treatment and Research is an Open Access Journal. All articles are distributed under the terms of the Creative Commons Attribution NonCommercial License (http://creativecommons.org/licenses/by-nc/4.0/) which permits unrestricted non-commercial use, distribution, and reproduction in any medium, provided the original work is properly cited. 
as lymphedema and axillary nerve damage, which can lead to poor quality of life [3-5].

Sentinel lymph node biopsy (SLNB) is considered a standard procedure for histologically identifying axillary lymph node metastasis in clinically node-negative breast cancer. With the introduction of SLNB, the number of ALNDs has decreased compared to that in the past. Furthermore, several clinical trials have been conducted on procedures that can be used to omit ALND even in SLNB with 1 or 2 axillary lymph node metastases [6-8]. The American College of Surgeons Oncology Group (ACOSOG) Z0011, a randomized trial, reported that there was no effect on the survival rate after omission of ALND for 1 or 2 lymph node metastases identified in SLNB in early breast cancer patients who underwent breast conservative surgery (BCS) [9]. In addition, as breast screening examination increases the early detection of breast cancer, the number of early breast cancer patients has increased [10,11].

Although BCS is mostly performed in patients with early breast cancer, total mastectomy (TM) may be inevitable depending on various factors such as tumor location. Furthermore, the rate of mastectomy has increased again since 2013. This is because advances in imaging diagnosis such as magnetic resonance imaging have made it easier to diagnose a wide range of breast cancer and multiple breast cancers, and the National Health Insurance Service covers breast reconstruction for breast cancer and actively reflects patients' opinions on fear of recurrence or expectations of improved survival [12-14]. However, although several studies have suggested that radiation therapy, usually involved in BCS, may have a therapeutic effect on residual lymph nodes $[15,16]$, lymph node metastasis in patients undergoing TM without radiotherapy has rarely been studied with SLNB alone. We used data from the Korean Breast Cancer Society registration system (KBCR) to evaluate the usefulness of ALND in patients with early breast cancer who had undergone TM with 1 or 2 lymph node metastases in the final pathology.

\section{METHODS}

\section{Study design}

This study enrolled patients older than 18 years with early breast cancer who underwent TM. The large-scale data of the KBCR were retrospectively analyzed. Since 1996, the KBCR has collected data from 110 training hospitals nationwide in Korea. The cause and date of death in these data were used in connection with the data of the Korea Central Cancer Registry (Ministry of Health and Welfare in collaboration with the Korean National Statistical Office) to compile complete death statistics which were updated through 2014. The study was approved by the Institutional Review Board of Daejeon St. Mary's Hospital (No. DC18RESI0041). The inclusion criteria were: TM and SLNB, pathologic T stage 1 or 2, clinically negative axillary lymph nodes, 1 or 2 positive axillary lymph nodes on final pathology, no radiation therapy, and no neoadjuvant therapy.

The basic clinical characteristics of patients assessed include

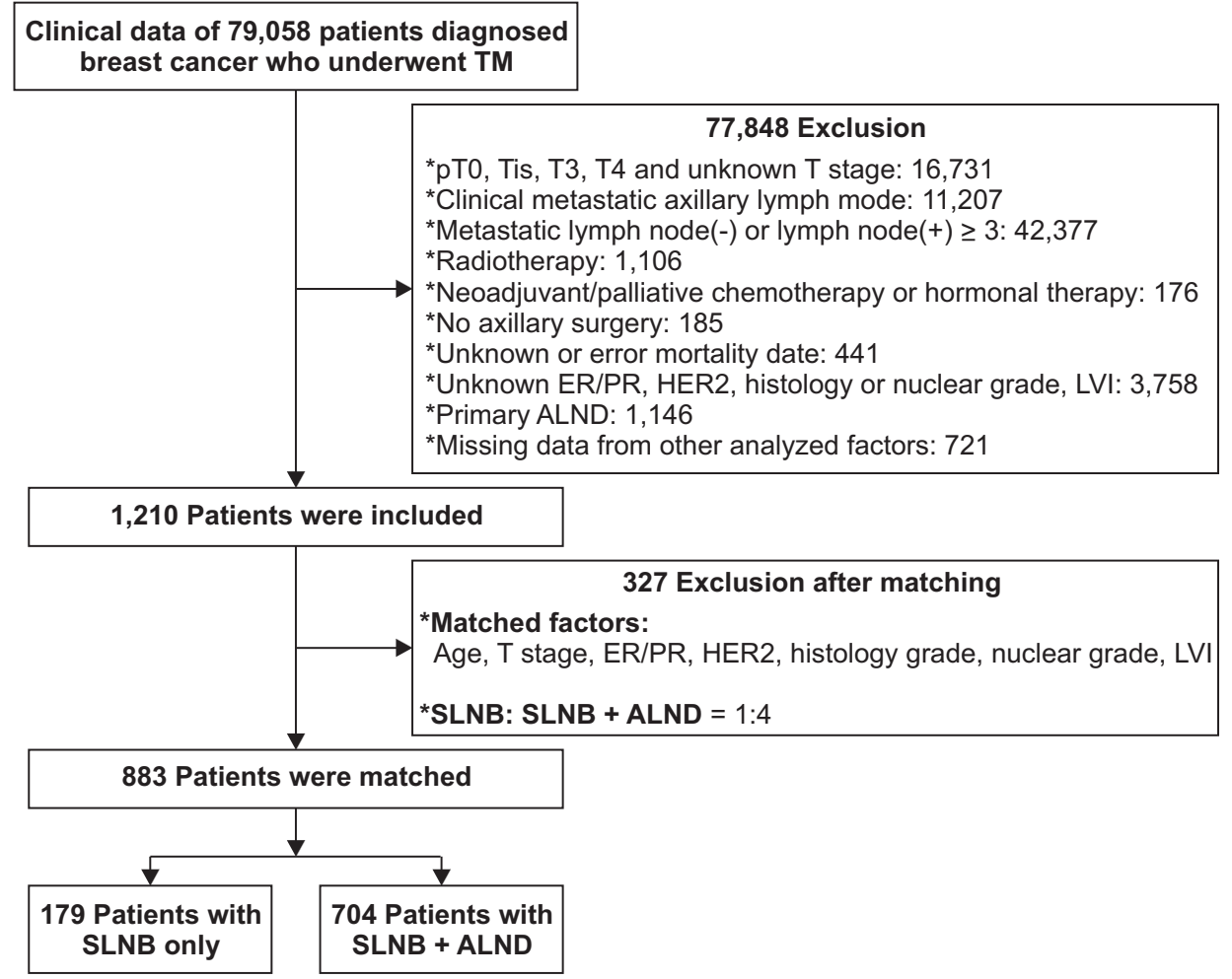

Fig. 1. Selection and matching of patients who underwent total mastectomy (TM). ER, estrogen receptor; PR, progesterone receptor; HER2, human epidermal growth receptor 2; LVI, lymphovascular invasion; ALND, axillary lymph node dissection; SLNB, sentinel lymph node biopsy. 
axillary operation method, age, pathologic $\mathrm{T}$ stage, lymph node status, immunohistochemistry, histologic type, histologic grade, nuclear grade, lymphovascular invasion, number of metastatic lymph nodes, total number of lymph nodes, family history, menopausal status, position of tumor, adjuvant chemotherapy or hormonal therapy, and overall survival (OS).

As 2 groups for analysis, the SLNB only and SLNB + ALND groups were matched according to the maximum propensity scores (1:4). The factors matched included age, pathologic $T$ stage, estrogen receptor or progesterone receptor status, human epidermal growth receptor 2 status, histologic grade, nuclear grade, and lymphovascular invasion. The primary endpoint was a comparison of the OS differences between the 2 groups. In addition, a subgroup analysis was performed to confirm the OS according to the axillary operation method for each clinical factor.

\section{Study population}

A total of 79,058 patients who underwent mastectomy were excluded as they did not meet the inclusion criteria or had insufficient data. The remaining 1,210 patients were matched by propensity scores using the matched factors, and a total of 883 patients were included in the analysis (Fig. 1). In addition, we compared the annual incidences of the SLNB only and SLNB + ALND groups among patients who met the diagnostic inclusion criteria: pathologic T stage 1 or 2, clinically negative axillary lymph nodes, and 1 or 2 metastatic axillary lymph nodes in the final pathology.

\section{Statistical analysis}

The clinical characteristics of patients in the matched cohort were compared using the chi-square test and the Student t-test. The differences in survival between the 2 groups were assessed via multivariate logistic regression analysis, the Kaplan-Meier method, and Cox proportional hazards regression analysis. Subgroup analysis, according to clinical factors, was used to identify factors that yielded differences in survival according to additional ALND. All statistical analyses were performed using IBM SPSS Statistics ver. 22.0 (IBM Co., Armonk, NY, USA), and $\mathrm{P}$-value $<0.05$ was considered statistically significant.

\section{RESULTS}

\section{Annual incidence of SLNB only or SLNB + ALND among patients who underwent TM with 1 or 2 metastatic axillary lymph nodes}

Of the 79,058 patients who underwent TM, 3,632 patients were met the diagnostic inclusion criteria. The numbers of performed SLNB only and SLNB + ALND have increased respectively and the proportion of only received SLNB also has increased from 1999 to 2015 (Fig. 2).

\section{Clinical characteristics}

Among the 883 patients in the matched cohort from 1999 to 2014, the median follow-up period was $54.00 \pm 36.946$ months. Apart from the histologic type $(\mathrm{P}=0.019)$, number of metastatic lymph nodes $(\mathrm{P}<0.001)$, total number of lymph nodes $(\mathrm{P}<$ $0.001)$, and chemotherapy $(P<0.001)$, there were no significant differences in the other characteristics between the 2 groups (Table 1).

\section{Factors associated with axillary dissection and survival}

Multivariate logistic regression of factors apart from those matched revealed that ALND was more frequent among patients with 2 metastatic lymph nodes, invasive ductal carcinoma, and chemotherapy (Table 2) and that hormonal therapy significantly improved the OS (Table 3).

Kaplan-Meier survival analysis revealed no difference in OS between the SLNB only and SLNB + ALND groups $(P=0.396)$ (Fig. 3).

The Cox proportional hazards model revealed no difference in OS between the SLNB only and SLNB + ALND groups (hazard ratio $[\mathrm{HR}], 0.728 ; \mathrm{P}=0.413)$. Only hormonal therapy showed a

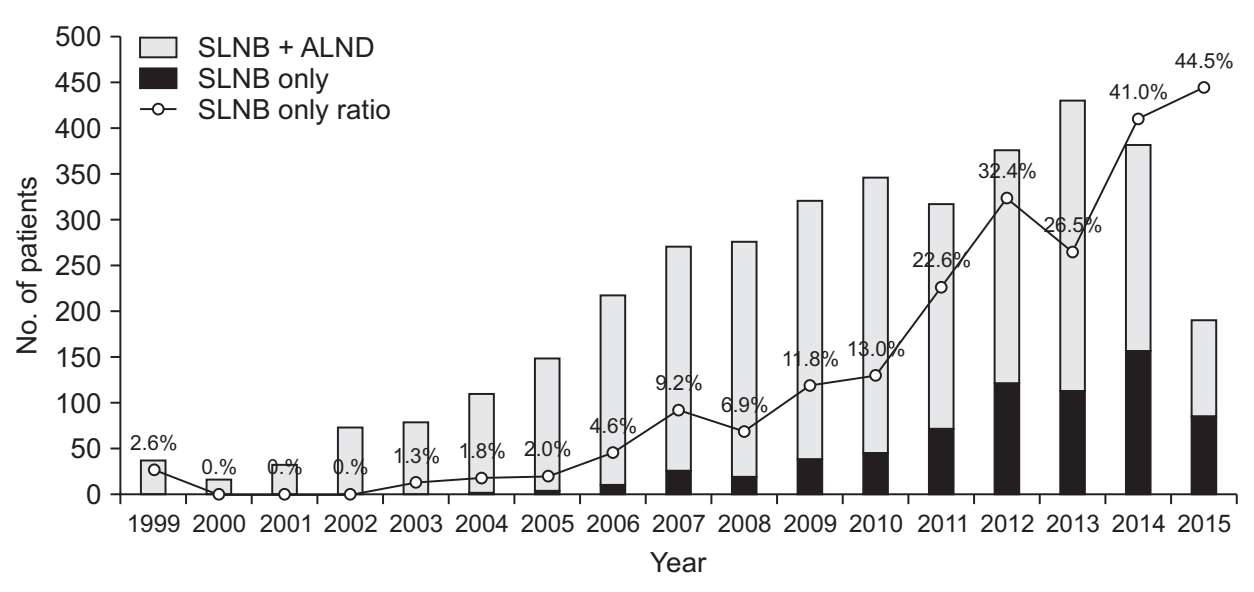

Fig. 2. Annual incidence of axillary operation in the patients who met the diagnostic inclusion criteria. SLNB, sentinel lymph node biopsy; ALND, axillary lymph node dissection. 
Table 1. Clinical characteristics of axillary sentinel lymph node biopsy and additional axillary lymph node dissection

\begin{tabular}{|c|c|c|c|}
\hline Characteristic & SLNB only $(\mathrm{n}=179,20.3 \%)$ & SLNB + ALND $(n=704,79.7 \%)$ & P-value \\
\hline Age (yr) & $50.78 \pm 12.34$ & $50.81 \pm 11.44$ & 0.972 \\
\hline$<50$ & $105(58.7)$ & $413(58.7)$ & 0.999 \\
\hline$\geq 50$ & $74(41.3)$ & $291(41.3)$ & \\
\hline \multicolumn{4}{|l|}{ T stage } \\
\hline $\mathrm{T} 1$ & $83(46.4)$ & $326(46.3)$ & 0.988 \\
\hline $\mathrm{T} 2$ & $96(53.6)$ & $378(53.7)$ & \\
\hline \multicolumn{4}{|l|}{ ER or PR } \\
\hline No & $27(15.1)$ & $104(14.8)$ & 0.917 \\
\hline Yes & $152(84.9)$ & $600(85.2)$ & \\
\hline \multicolumn{4}{|l|}{ HER2 } \\
\hline No & $137(76.5)$ & $545(77.4)$ & 0.802 \\
\hline Yes & $42(23.5)$ & $159(22.6)$ & \\
\hline \multicolumn{4}{|l|}{ Histologic type } \\
\hline IDC & $160(89.4)$ & $668(94.9)$ & 0.019 \\
\hline ILC & $14(7.8)$ & $29(4.1)$ & \\
\hline Others & $5(2.8)$ & $7(1.0)$ & \\
\hline \multicolumn{4}{|l|}{ Histology grade } \\
\hline G1-2 & $130(72.6)$ & $515(73.2)$ & 0.887 \\
\hline G3 & $49(27.4)$ & $189(26.8)$ & \\
\hline \multicolumn{4}{|l|}{ Nuclear grade } \\
\hline G1-2 & $126(70.4)$ & $501(71.2)$ & 0.839 \\
\hline G3 & $53(29.6)$ & $203(28.8)$ & \\
\hline \multicolumn{4}{|l|}{ Lymphovascular invasion } \\
\hline No & $101(56.4)$ & $400(56.8)$ & 0.924 \\
\hline Yes & $78(43.6)$ & $304(43.2)$ & \\
\hline \multicolumn{4}{|c|}{ No. of metastatic lymph nodes } \\
\hline 1 & $159(88.8)$ & $476(67.6)$ & $<0.001$ \\
\hline 2 & $20(11.2)$ & $288(32.4)$ & \\
\hline Total No. of lymph nodes & $6.72 \pm 5.70$ & $16.16 \pm 7.50$ & $<0.001$ \\
\hline \multicolumn{4}{|l|}{ Family history } \\
\hline No & $162(90.5)$ & $642(91.2)$ & 0.773 \\
\hline Yes & $17(9.5)$ & $62(8.8)$ & \\
\hline \multicolumn{4}{|l|}{ Menopause } \\
\hline No & $105(58.7)$ & $399(56.7)$ & 0.632 \\
\hline Yes & $74(41.3)$ & $305(43.3)$ & \\
\hline \multicolumn{4}{|l|}{ Position of tumor } \\
\hline Inner & $37(20.7)$ & $157(22.3)$ & 0.319 \\
\hline Outer & $116(64.8)$ & $416(59.1)$ & \\
\hline Central & $26(14.5)$ & $131(18.6)$ & \\
\hline \multicolumn{4}{|l|}{ Chemotherapy } \\
\hline No & $43(24.0)$ & $66(9.4)$ & $<0.001$ \\
\hline Yes & $136(76.0)$ & $638(90.6)$ & \\
\hline \multicolumn{4}{|l|}{ Hormonal therapy } \\
\hline No & $34(19.0)$ & $127(18.0)$ & 0.768 \\
\hline Yes & $145(81.0)$ & $577(82.0)$ & \\
\hline \multicolumn{4}{|l|}{ Overall survival } \\
\hline No & $171(95.5)$ & $646(91.8)$ & 0.087 \\
\hline Yes & $8(4.5)$ & $58(8.2)$ & \\
\hline
\end{tabular}

Values are presented as mean \pm standard deviation or number $(\%)$.

SLNB, axillary sentinel lymph node biopsy; ALND, axillary lymph node dissection; ER, estrogen receptor; PR, progesterone receptor; HER2, human epidermal growth receptor 2; IDC, invasive ductal carcinoma; ILC, invasive lobular carcinoma. 
Table 2. Multivariate analysis for clinical factors associated with axillary operation

\begin{tabular}{lccc}
\hline \multicolumn{1}{c}{ Characteristic } & OR & $95 \% \mathrm{Cl}$ & P-value \\
No. of metastatic lymph nodes & & & \\
1 & 1.000 & & - \\
2 & 3.445 & $2.094-5.668$ & $<0.001$ \\
Family history & & & \\
$\quad$ No & 1.000 & & - \\
Yes & 0.922 & $0.512-1.662$ & 0.788 \\
Menopause & & & \\
No & 1.000 & & - \\
Yes & 1.265 & $0.886-1.806$ & 0.196 \\
Position of tumor & & & \\
$\quad$ Inner & 1.000 & & - \\
Outer & 0.845 & $0.550-1.299$ & 0.443 \\
Central & 1.160 & $0.654-2.056$ & 0.612 \\
Histologic type & & & \\
IDC & 1.000 & & - \\
ILC & 0.500 & $0.251-0.997$ & 0.049 \\
Others & 0.582 & $0.174-1.951$ & 0.381 \\
Chemotherapy & & & \\
No & 1.000 & & - \\
Yes & 2.770 & $1.772-4.331$ & $<0.001$ \\
Hormonal therapy & & & \\
No & 1.000 & & - \\
Yes & 1.134 & $0.730-1.762$ & 0.575 \\
\hline OR odds ras & & & \\
\hline
\end{tabular}

OR, odds ratio; $\mathrm{Cl}$, confidence interval; IDC, invasive ductal carcinoma; ILC, invasive lobular carcinoma.

significant survival benefit (HR, 0.337; P < 0.001) (Table 4).

\section{Subgroup analysis}

In the subgroup analysis, SLNB + ALND among patients in the stage T2 group showed survival benefits when assessed via Cox proportional hazards model divided by immunohistochemistry, age, $\mathrm{T}$ stage, number of metastatic lymph nodes, and histologic type (HR, 0.356; $\mathrm{P}=0.013$ ) (Fig. 4).

\section{DISCUSSION}

Our study revealed that additional ALND did not affect the survival rate among early breast cancer patients who underwent TM and SLNB with 1 or 2 axillary lymph node metastasis in the final pathology. In the ACOSOG Z0011, the median followup period among enrolled patients with 1 or 2 pathologically identified positive lymph nodes from SLNB was 6.3 years; the 5-year OS was $92.5 \%$ with SLNB and $91.8 \%$ with ALND [9]. Our study included patients with 1 or 2 metastatic lymph nodes in the final pathology, unlike the ACOSOG Z0011. The median follow-up period was 4.5 years, and the 5-year OS was $88.8 \%$ with SLNB and $93.6 \%$ with ALND. Similar to the present study, Lee et al. [17] reported that there was no difference in OS regardless of ALND among patients with early breast cancer
Table 3. Clinical factors associated with overall survival

\begin{tabular}{|c|c|c|c|}
\hline Characteristic & OR & $95 \% \mathrm{Cl}$ & P-value \\
\hline \multicolumn{4}{|l|}{ Axillary operation } \\
\hline SLNB only & 1.000 & & - \\
\hline SLNB + ALND & 2.045 & $0.920-4.546$ & 0.079 \\
\hline \multicolumn{4}{|c|}{ No. of metastatic lymph nodes } \\
\hline 1 & 1.000 & & - \\
\hline 2 & 1.223 & $0.702-2.129$ & 0.477 \\
\hline \multicolumn{4}{|l|}{ Family history } \\
\hline No & 1.000 & & - \\
\hline Yes & 0.760 & $0.291-1.985$ & 0.575 \\
\hline \multicolumn{4}{|l|}{ Menopause } \\
\hline No & 1.000 & & - \\
\hline Yes & 0.734 & $0.427-1.260$ & 0.262 \\
\hline \multicolumn{4}{|l|}{ Position of tumor } \\
\hline Inner & 1.000 & & - \\
\hline Outer & 1.258 & $0.634-2.496$ & 0.511 \\
\hline Central & 2.184 & $0.990-4.817$ & 0.053 \\
\hline \multicolumn{4}{|l|}{ Histologic type } \\
\hline IDC & 1.000 & & \\
\hline ILC & 1.611 & $0.544-4.771$ & 0.389 \\
\hline Others & $<0.001$ & - & 0.999 \\
\hline \multicolumn{4}{|l|}{ Chemotherapy } \\
\hline No & 1.000 & & - \\
\hline Yes & 0.657 & $0.301-1.437$ & 0.293 \\
\hline \multicolumn{4}{|l|}{ Hormonal therapy } \\
\hline No & 1.000 & & - \\
\hline Yes & 0.297 & $0.170-0.520$ & $<0.001$ \\
\hline
\end{tabular}

OR, odds ratio; $\mathrm{Cl}$, confidence interval; SLNB, axillary sentinel lymph node biopsy; ALND, axillary lymph node dissection; IDC, invasive ductal carcinoma; ILC, invasive lobular carcinoma.

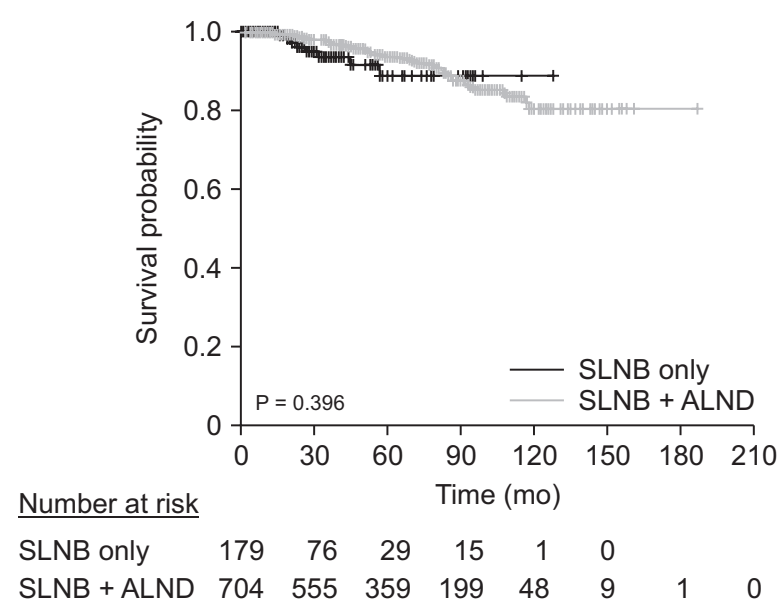

Fig. 3. Survival curves of SLNB group and SLNB + ALND group. SLNB, sentinel lymph node biopsy; ALND, axillary lymph node dissection.

who underwent BCS with 1 or 2 positive lymph nodes in the final pathology. FitzSullivan et al. [18] reported that there was no significant difference in recurrence-free survival and OS among patients with metastatic lymph nodes from TM and 
SLNB regardless of additional ALND or irradiation. In this regard, the omission of ALND may be expected to reduce morbidity and improve the quality of life among early breast cancer patients who underwent TM and SLNB with 1 or 2 axillary lymph node metastasis.

Table 4. Prognostic factors of overall survival

\begin{tabular}{|c|c|c|c|}
\hline Characteristic & $H R$ & $95 \% \mathrm{Cl}$ & P-value \\
\hline \multicolumn{4}{|l|}{ Axillary operation } \\
\hline SLNB only & 1.000 & & - \\
\hline SLNB + ALND & 0.728 & $0.340-1.557$ & 0.413 \\
\hline \multicolumn{4}{|c|}{ No. of metastatic lymph nodes } \\
\hline 1 & 1.000 & & - \\
\hline 2 & 1.228 & $0.728-2.071$ & 0.442 \\
\hline \multicolumn{4}{|l|}{ Family history } \\
\hline No & 1.000 & & - \\
\hline Yes & 0.774 & $0.305-1.964$ & 0.589 \\
\hline \multicolumn{4}{|l|}{ Menopause } \\
\hline No & 1.000 & & - \\
\hline Yes & 0.743 & $0.439-1.259$ & 0.270 \\
\hline \multicolumn{4}{|l|}{ Position of tumor } \\
\hline Inner & 1.000 & & - \\
\hline Outer & 1.244 & $0.645-2.400$ & 0.515 \\
\hline Central & 1.541 & $0.731-3.248$ & 0.256 \\
\hline \multicolumn{4}{|l|}{ Histologic type } \\
\hline IDC & 1.000 & & \\
\hline ILC & 1.807 & $0.641-5.095$ & 0.263 \\
\hline Others & $<0.001$ & - & 0.969 \\
\hline \multicolumn{4}{|l|}{ Chemotherapy } \\
\hline No & 1.000 & & - \\
\hline Yes & 0.505 & $0.239-1.066$ & 0.073 \\
\hline \multicolumn{4}{|l|}{ Hormonal therapy } \\
\hline No & 1.000 & & - \\
\hline Yes & 0.337 & $0.200-0.568$ & $<0.001$ \\
\hline
\end{tabular}

$\mathrm{HR}$, hazard ratio; $\mathrm{Cl}$, confidence interval; SLNB, axillary sentinel lymph node biopsy; ALND, axillary lymph node dissection; IDC, invasive ductal carcinoma; ILC, invasive lobular carcinoma.
In this study, there were some cases where ALND was omitted prior to the announcement of the ACOSOG Z0011 results. Since the design of our study is retrospective, we were not able to determine the exact reason why ALND was omitted on such cases. However, given that there were several studies prior to 2011 on the omission of ALND in breast cancer patients with favorable features $[19,20]$, we presumed that those studies provided basis for ALND omission.

There was no difference in adjuvant chemotherapy rates between the SLNB and ALND groups in ACOSOG Z0011. However, in our study, the adjuvant chemotherapy rate was relatively higher in the SLNB + ALND group (90.6\%) than in the SLNB only group $(76.0 \%)(\mathrm{P}<0.001)$. Considering that $27.3 \%$ of patients had nonsentinel lymph node metastasis in ACOSOG Z0011 [21], although there is a possibility that some metastatic lymph nodes remain and the relatively low adjuvant chemotherapy rates in the SLNB only group of our study, the lack of difference in survival seems to be a meaningful result.

The survival rate was higher among patients who received hormonal therapy than among those who did not. This seems to be in the same context that, as is known, patients with hormone receptor positive disease showed a better survival rate than did those with hormone receptor negative disease [22-25].

The most common histologic type in this study was invasive ductal carcinoma, and invasive lobular carcinoma was rare (4.9\%). The proportion of patients with invasive lobular carcinoma was relatively high in the SLNB only group, but there was no difference in survival rate according to histologic type. In some studies, ALND was not related to survival in invasive lobular carcinoma meeting the ACOSOG Z0011 criteria [26,27].

In the subgroup analysis, unlike the $\mathrm{T} 1$ subgroup, additional ALND resulted in a significantly higher survival benefit than SLNB only in the T2 subgroup. Considering that nonsentinel lymph node metastasis was related to tumor size in other studies [28,29], even if it is included in the category of early

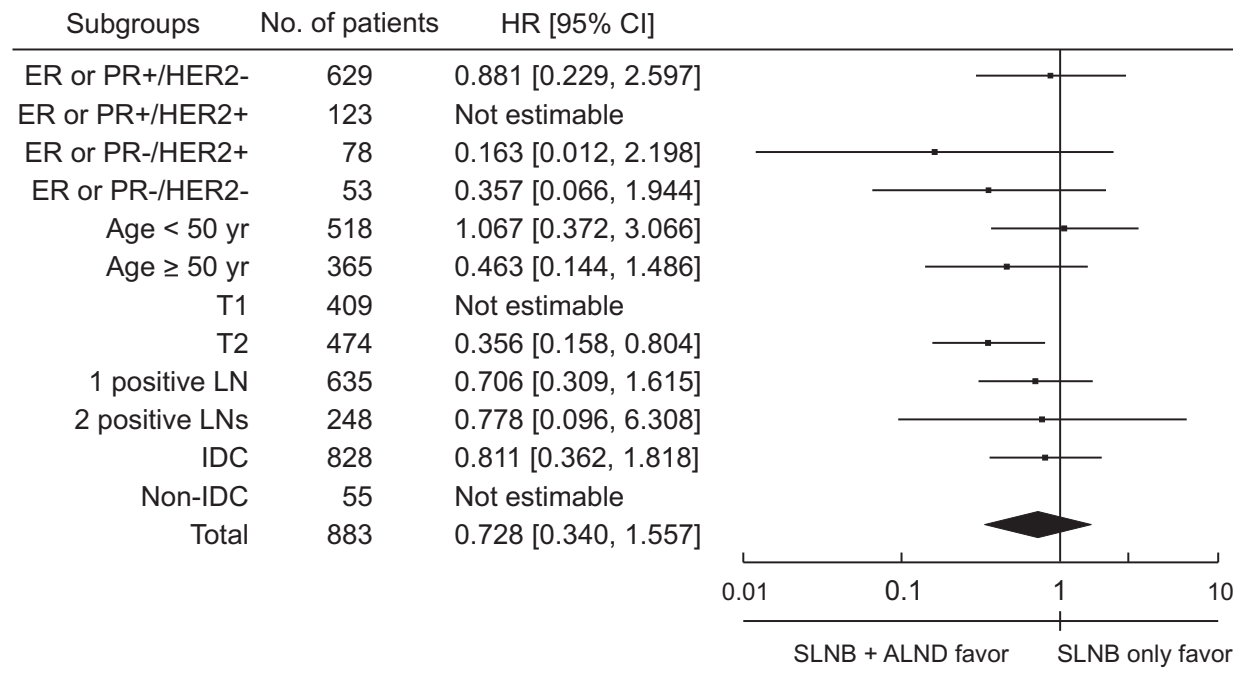

Fig. 4. Subgroup analysis of clinical factors affecting overall survivals of axillary operation. $\mathrm{HR}$, hazard ratio; $\mathrm{Cl}$, confidence interval; ER, estrogen receptor; $\mathrm{PR}$, progesterone receptor; HER2, human epidermal growth receptor 2; LN, lymph node; IDC, invasive ductal carcinoma; SLNB, sentinel lymph node biopsy; ALND, axillary lymph node dissection. 
breast cancer, it is necessary to subdivide it to consider additional ALND.

In ACOSOG Z0011, tangential field whole breast irradiation was performed after BCS in all patients, which partially included or did not include the axillary field $[15,16]$. Radiotherapy as adjuvant therapy was the main target of residual breast tissue after BCS. Axillary irradiation may have been secondarily included in the tangential field according to the radiologist's findings, but this was not the main adjuvant therapy. In this study, TM itself was not an indication for tangential field whole breast irradiation. In AMAROS trial, there was no difference in survival between the ALND group and the axillary radiotherapy group in early breast cancer patients with sentinel lymph node metastasis [30]. On this basis, adjuvant radiotherapy after TM was excluded to rule out the effects of adjuvant therapy in the axillary field.

The main strengths of this study were that we reduced confounders via propensity score matching and increased the reliability by assessing more homogenous populations. However, this study has several limitations. First, it was a retrospective study. Additionally, limited information was available on prognosis, such as recurrence or breast cancer specific survival. Then, prognosis was assessed using OS. However, there was a possibility that other factors might have been involved in mortality. Furthermore, in the SLNB + ALND group, the total and metastatic lymph nodes were registered as the mixture of data regarding sentinel lymph nodes and additional dissected lymph nodes, which limited their further analysis. Most of the analysis data contained data from 2010 onwards, so the follow-up period was rather short. Finally, the matched factors were mainly the pathological factors of breast cancer, and there is a possibility that the analysis result might be influenced by selection bias of other unmatched factors.

In this study, we confirmed that there was no difference in the patients' survival rate regardless of additional ALND even among early breast cancer patients who underwent TM and
SLNB with 1 or 2 axillary lymph node metastases in the final pathology. Although further studies are needed, omission of ALND may be considered in selected patients.

\section{ACKNOWLEDGEMENTS}

\section{Fund/Grant Support}

This article was supported by the Korean Breast Cancer Society, which provided data.

\section{Conflict of Interest}

No potential conflict of interest relevant to this article was reported.

\section{ORCID iD}

Bong Kyun Kim: https://orcid.org/0000-0002-3845-9584

Byeong-Woo Park: https://orcid.org/0000-0003-1353-2607

Min Hee Hur: https://orcid.org/0000-0002-3908-2555

Han-Byoel Lee: https://orcid.org/0000-0003-0152-575X

Min Ho Park: https://orcid.org/0000-0002-7046-3874

Joon Jeong: https://orcid.org/0000-0003-0397-0005

Hyouk Jin Lee: https://orcid.org/0000-0002-6579-3529

Jina Lee: https://orcid.org/0000-0002-8565-1720

Dongju Kim: https://orcid.org/0000-0002-5631-7176

Woo Young Sun: https://orcid.org/0000-0002-5447-4266

\section{Author Contribution}

Conceptualization: WYS

Formal Analysis: BKK

Investigation: WYS, BKK, JL, DK

Methodology: BKK

Project Administration: BWP, MHH, HBL, MHP, JJ, HJL

Writing - Original Draft: BKK

Writing - Review \& Editing: WYS, BWP, MHH, HBL, MHP, JJ, HJL, JL, DK

\section{REFERENCES}

1. Halsted WS. I. A clinical and histological study of certain adenocarcinomata of the breast: and a brief consideration of the supraclavicular operation and of the results of operations for cancer of the breast from 1889 to 1898 at the Johns Hopkins Hospital. Ann Surg 1898:28:557-76.

2. Halsted WS. I. The results of radical operations for the cure of carcinoma of the breast. Ann Surg 1907:46:1-19.

3. Khan F, Amatya B, Pallant JF, Rajapaksa

I. Factors associated with long-term functional outcomes and psychological sequelae in women after breast cancer. Breast 2012;21:314-20.

4. Armer JM. The problem of post-breast cancer lymphedema: impact and measurement issues. Cancer Invest 2005;23:76-83.
5. Bulley C, Coutts F, Blyth C, Jack W, Chetty U, Barber M, et al. A Morbidity Screening Tool for identifying fatigue, pain, upper limb dysfunction and lymphedema after breast cancer treatment: a validity study. Eur J Oncol Nurs 2014;18:218-27.

6. Krag DN, Anderson SJ, Julian TB, Brown AM, Harlow SP, Costantino JP, et al. Sentinel-lymph-node resection compared 
with conventional axillary-lymph-node dissection in clinically node-negative patients with breast cancer: overall survival findings from the NSABP B-32 randomised phase 3 trial. Lancet Oncol 2010;11:927-33.

7. Galimberti V, Cole BF, Zurrida S, Viale G, Luini A, Veronesi P, et al. Axillary dissection versus no axillary dissection in patients with sentinel-node micrometastases (IBCSG 23-01): a phase 3 randomised controlled trial. Lancet Oncol 2013;14:297-305.

8. Sola M, Alberro JA, Fraile M, Santesteban P, Ramos M, Fabregas R, et al. Complete axillary lymph node dissection versus clinical follow-up in breast cancer patients with sentinel node micrometastasis: final results from the multicenter clinical trial AATRM 048/13/2000. Ann Surg Oncol 2013;20:120-7.

9. Giuliano AE, Hunt KK, Ballman KV, Beitsch PD, Whitworth PW, Blumencranz PW, et al. Axillary dissection vs no axillary dissection in women with invasive breast cancer and sentinel node metastasis: a randomized clinical trial. JAMA 2011;305:569-75.

10. Bleyer A, Welch HG. Effect of three decades of screening mammography on breast-cancer incidence. N Engl J Med 2012;367:1998-2005.

11. Iqbal J, Ginsburg O, Rochon PA, Sun P, Narod SA. Differences in breast cancer stage at diagnosis and cancer-specific survival by race and ethnicity in the United States. JAMA 2015:313:165-73.

12. Kang SY, Kim YS, Kim Z, Kim HY, Lee SK, Jung KW, et al. Basic findings regarding breast cancer in Korea in 2015: data from a Breast Cancer Registry. J Breast Cancer 2018;21:1-10.

13. Miller BT, Abbott AM, Tuttle TM. The influence of preoperative MRI on breast cancer treatment. Ann Surg Oncol 2012:19:536-40.

14. Hong KY, Son Y, Chang H, Jin US. Trends in breast reconstruction: implications for the National Health Insurance Service. Arch Plast Surg 2018;45:239-45.

15. Belkacemi Y, Allab-Pan Q, Bigorie V,
Khodari W, Beaussart P, Totobenazara JL, et al. The standard tangential fields used for breast irradiation do not allow optimal coverage and dose distribution in axillary levels I-II and the sentinel node area. Ann Oncol 2013;24:2023-8.

16. Giuliano AE, Ballman K, McCall L, Beitsch P, Whitworth PW, Blumencranz P, et al. Locoregional recurrence after sentinel lymph node dissection with or without axillary dissection in patients with sentinel lymph node metastases: longterm follow-up from the American College of Surgeons Oncology Group (Alliance) ACOSOG Z0011 Randomized Trial. Ann Surg 2016;264:413-20.

17. Lee J, Choi JE, Kim SJ, Lee SB, Seong MK, Jeong J, et al. Comparative study between sentinel lymph node biopsy and axillary dissection in patients with one or two lymph node metastases. J Breast Cancer 2018;21:306-14.

18. FitzSullivan E, Bassett RL, Kuerer HM, Mittendorf EA, Yi M, Hunt KK, et al. Outcomes of sentinel lymph node-positive breast cancer patients treated with mastectomy without axillary therapy. Ann Surg Oncol 2017:24:652-9.

19. Van Zee KJ, Manasseh DM, Bevilacqua JL, Boolbol SK, Fey JV, Tan LK, et al. A nomogram for predicting the likelihood of additional nodal metastases in breast cancer patients with a positive sentinel node biopsy. Ann Surg Oncol 2003;10: 1140-51.

20. Park J, Fey JV, Naik AM, Borgen PI, Van Zee KJ, Cody HS 3rd. A declining rate of completion axillary dissection in sentinel lymph node-positive breast cancer patients is associated with the use of a multivariate nomogram. Ann Surg 2007;245:462-8.

21. Giuliano AE, Ballman KV, McCall L, Beitsch PD, Brennan MB, Kelemen PR, et al. Effect of axillary dissection vs no axillary dissection on 10-year overall survival among women with invasive breast cancer and sentinel node metastasis: the ACOSOG Z0011 (Alliance) Randomized Clinical Trial. JAMA 2017;318:918-26.

22. Knight WA, Livingston RB, Gregory EJ, McGuire WL. Estrogen receptor as an independent prognostic factor for early recurrence in breast cancer. Cancer Res 1977:37:4669-71.

23. Parl FF, Schmidt BP, Dupont WD, Wagner RK. Prognostic significance of estrogen receptor status in breast cancer in relation to tumor stage, axillary node metastasis, and histopathologic grading. Cancer 1984:54:2237-42.

24. Parise CA, Caggiano V. Risk of mortality of node-negative, ER/PR/HER2 breast cancer subtypes in $\mathrm{T} 1, \mathrm{~T} 2$, and $\mathrm{T} 3$ tumors. Breast Cancer Res Treat 2017;165:743-50.

25. Kim H, Cho J, Kwon SY, Kang SH. Biologic subtype is a more important prognostic factor than nodal involvement in patients with stages I and II breast carcinoma. Ann Surg Treat Res 2016;90:1-9.

26. Roberts A, Nofech-Mozes S, Youngson B, McCready DR, Al-Assi M, Ramkumar S, et al. The importance of applying ACOSOG Z0011 criteria in the axillary management of invasive lobular carcinoma: a multiinstitutional cohort study. Ann Surg Oncol 2015;22:3397-401.

27. Wang J, Mittendorf EA, Sahin AA, Yi M, Caudle A, Hunt KK, et al. Outcomes of sentinel lymph node dissection alone vs. axillary lymph node dissection in early stage invasive lobular carcinoma: a retrospective study of the surveillance, epidemiology and end results (SEER) database. PLoS One 2014:9:e89778.

28. Loza CM, Mando P, Ponce C, Colo F, Fabiano V, Loza J, et al. Predictive factors for non-sentinel lymph node metastasis in patients with ACOSOG Z0011 criteria. Breast Care (Basel) 2018:13:434-8.

29. Ozmen V, Karanlik H, Cabioglu N, Igci A, Kecer M, Asoglu O, et al. Factors predicting the sentinel and non-sentinel lymph node metastases in breast cancer. Breast Cancer Res Treat 2006;95:1-6.

30. Donker M, van Tienhoven G, Straver ME, Meijnen P, van de Velde CJ, Mansel RE, et al. Radiotherapy or surgery of the axilla after a positive sentinel node in breast cancer (EORTC 10981-22023 AMAROS): a randomised, multicentre, open-label, phase 3 non-inferiority trial. Lancet Oncol 2014;15:1303-10. 